memo (2018) 11:80

https://doi.org/10.1007/s12254-018-0382-4

\title{
Correction to: Report from the WCLC 2017 Congress, Yokohama, 15th-18th October, 2017
}

\section{Springer-Verlag GmbH Austria}

Published online: 21 February 2018

(C) Springer-Verlag GmbH Austria, part of Springer Nature 2018

\section{Correction to:} memo 2017

https://doi.org/10.1007/s12254-017-0381-X

Unfortunately, the title of this article was published incorrect.

The correct title is: Report from the WCLC 2017 Congress, Yokohama, 15t-18th October, 2017.

The original article has been corrected.

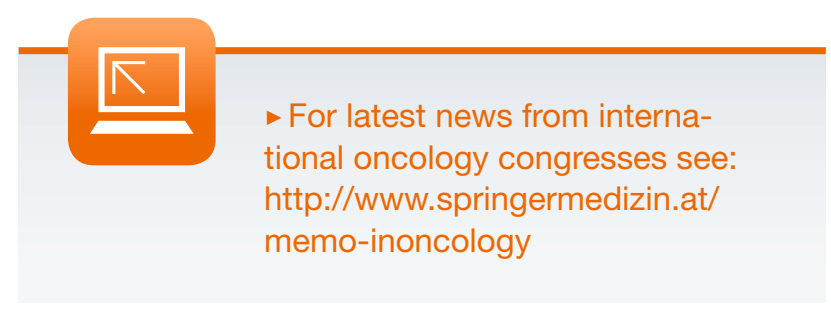

The online version of the original article can be found under https://doi.org/10.1007/s12254-017-0381-x.

Springer-Verlag GmbH Austria $(\bowtie)$

Prinz-Eugen-Strasse 8-10, 1040 Vienna, Austria 